\title{
Synthesis and Structure of 2D Cobalt(II)-Tartrate Hydrate Coordination Polymers Crystallised from Aqueous Solution
}

\author{
Mohammad Misbah Khunur, Yuniar Ponco Prananto* \\ Department of Chemistry, Brawijaya University, Jl. Veteran 01 Malang, Indonesia
}

Received: $17^{\text {th }}$ July 2017; Revised: $30^{\text {th }}$ October 2017; Accepted: $30^{\text {th }}$ October 2017; Available online: $11^{\text {st }}$ June 2018; Published regularly: $1^{\text {st }}$ August 2018

\begin{abstract}
Cobalt(II)-tartrate hydrate coordination polymer is successfully crystallisedfrom aqueous solution at room temperature. Unlike previous methods, diammonium tartrate was used and reacted directly with an aqueous solution of cobalt(II). Single crystal X-ray and ATR-IR analyses were performed toward the synthesized crystal. The crystal structure displaysa $(6,3) 2 \mathrm{D}$ sheet which then grow into a 3D hydrogen-bonded network. Tetra- and hexa-dentate dianionic tartaric ligands are observed in the crystal structure, in which the hexadentate ligand connects four different cobalt centres. This method is considered feasible, affordable, and simple for the production of functional polymeric cobalt(II)tartrate hydrate. Copyright (C) 2018 BCREC Group. All rights reserved
\end{abstract}

Keywords: Diammonium tartrate; coordination polymers; aqueous solution; crystal structure; cobalt(II) tartrate

How to Cite: Khunur, M.M., Prananto, Y.P. (2018). Synthesis and Structure of 2D Cobalt(II)-tartrate Hydrate Coordination Polymers Crystallised from Aqueous Solution. Bulletin of Chemical Reaction Engineering \& Catalysis, 13 (2): 213-219 (doi:10.9767/bcrec.13.2.1342.213-219)

Permalink/DOI: https://doi.org/10.9767/bcrec.13.2.1342.213-219

\section{Introduction}

Coordination polymer (CPs), which is defined in IUPAC recommendation as "a coordination compound with repeating coordination entities extending in 1,2 , or 3 dimensions" [1], have been widely explored in the last several decades due to their interesting properties such as porosity, magnetism, catalysis, chirality, etc. [2]. Due to this, CPs have been developed for gas storage, solvent guest exchange, catalyst, drug delivery systems study, etc. [3,4]. Harvesting good quality single crystal of CPs is crucial for structural analyses using XRD. The crystal-

* Corresponding Author.

E-mail: prananto@ub.ac.id (Prananto, Y.P.)

Telp: +62-341-575838 lization and structure can be affected by solvents [5], anions [6], temperature [7], moles ratio, metal ion, etc. A simple change in the synthesis condition might change the structure and properties of CPs [4].

Carboxylate based compounds and their derivatives are often used as building blocks to obtain CPs. The carboxylate group, sometimes along with other functional groups incorporated into the ligand, coordinate effectively with the metal ion. In fact, dicarboxylate can act as a bridging ligand in the making of $\mathrm{CPs}$, for example, oxalate [8], malonate [9], succinate [10], tartrate [11], and benzenedicarboxylate [12]. Particularly tartrate, metal complexes of this anion have been explored since decades ago. Tartrate ion forms ionic bonding with the metal ion and their single crystal displays high optical non- 
linearity. It has also been developed for laser diodes in which different metal ion affects the material conductivity [13]. Tartrate inorganic salts are known for transducer [14] since ferroelectricity and piezoelectricity are commonly exhibited by their crystals [15-18].

Several methods to get tartrate complex were reported, namely solution, gel, and solvothermal. Melting method is considered unachievable, as tartrate will decompose before its melting point. Gel method gains the highest reputation to grow single crystal of tartrate metal complexes as most of these complexes are partly soluble in water [19]. However, this method deal with multi-steps and several factors such as $\mathrm{pH}$, type of gel, concentration, etc., must be incorporated. Crystallization of tartrate metal complexes using solvothermal reaction is only reported by few papers [11], as this method using high temperature, which may cause decomposition of the tartrate hence lower the yield, and require specific high-cost advance instruments. Solution method comes as the least method to produce good quality of tartrate metal complex single crystals since many tartrate complexes are partly soluble in water and may form amorphous products. Anyhow, solution method was chosen in this work because it is simple and the possibility of getting good quality single crystals can be increased by adjusting the reaction condition.

This paper presents the synthesis of cobalt(II)-tartrate hydrate coordination polymer in an aqueous solution using diammonium tartrate. Diammonium tartrate is never been used previously for cobalt(II)-tartrate synthesis. Cobalt(II)-tartrate is a useful compound and being used in the production of $\mathrm{Co}_{3} \mathrm{O}_{4}$ nanoparticles, [20], as well as for semiconductors, transducers, and optics, etc., due to its optical, electric and magnetic properties [21-23]. Many cobalt(II)-tartrate crystallised in silica gel and in some of the papers, the physical properties of the product were deeply examined but not structurally characterised [21-23], for example is cobalt(II)-tartrate hydrate crystals reported by Ariponnammal and Srinivasan which has $1.33 \mathrm{eV}$ energy gap and potential used for UV filters due to high absorption in UV-region (about $365.7 \mathrm{~nm}$ ) [24]. Cobalt(II)-tartrate could forms a discrete complex, such as: $\left[\mathrm{Co}\left(\mathrm{C}_{4} \mathrm{H}_{5} \mathrm{O}_{6}\right)_{2}\left(\mathrm{H}_{2} \mathrm{O}\right)_{2}\right] \cdot 2 \mathrm{H}_{2} \mathrm{O}$ [25] or coordination polymer, such as $\left\{\left[\mathrm{Co}_{2}\left(\mathrm{C}_{4} \mathrm{H}_{4} \mathrm{O}_{6}\right) 2\right] \cdot 2 \mathrm{H}_{2} \mathrm{O}\right\}_{\mathrm{n}}$ [11], depends on the synthetic method.

To the best of our knowledge, synthesizing cobalt(II)-tartrate hydrate single crystal prepared in an aqueous solution specifically using diammonium tartrate has never been reported.
Hence in this paper, we report the synthesis of and crystal structure of the cobalt(II)-tartrate hydrate coordination polymers. The crystal structure presented here is also different to previous works $[11,25]$.

\section{Materials and Method}

\subsection{Materials and measurements}

Sigma-Aldrich chemicals $\left(\mathrm{Co}\left(\mathrm{NO}_{3}\right)_{2} \cdot 6 \mathrm{H}_{2} \mathrm{O}\right.$ and $\left.\left(\mathrm{NH}_{4}\right)_{2}\left(\mathrm{C}_{4} \mathrm{H}_{4} \mathrm{O}_{6}\right)\right)$ were used as received. Solid-state IR spectra were recorded by using an Agilent ATR spectroscope at 4000-650 $\mathrm{cm}^{-1}$ with sensitivity of 3 . Low-temperature singlecrystal X-ray diffraction experiments were performed using a Bruker Apex II KAPPA CCD with Mo-Ka radiation (10.71073 $\AA$ ) equipped with an Oxford Instruments nitrogen gas cryostream. Single crystals were mounted on nylon loops in viscous hydrocarbon oil. Crystals were quench-cooled to 123(2) K. Analysis of diffraction data collected with the Bruker Apex II KAPPA CCD was performed by using SAINT1 within the APEX2 [26] software package. Empirical absorption corrections were applied to all data by using SADABS [27]. The structures were solved using SHELXS [28] and refined using SHELXL-13 [28-30] within the graphical interface Olex2 [31].

\subsection{Synthesis of the complex}

Diammonium tartrate, $\left(\mathrm{NH}_{4}\right)_{2}\left(\mathrm{C}_{4} \mathrm{H}_{4} \mathrm{O}_{6}\right)$, (50 $\mathrm{mg} ; 0.271 \mathrm{mmol}$ ) was dissolved in $10 \mathrm{~mL}$ water. The solution then added slowly to an aqueous solution of $\mathrm{Co}\left(\mathrm{NO}_{3}\right)_{2} \cdot 6 \mathrm{H}_{2} \mathrm{O} \quad(78.8 \mathrm{mg}, \quad 0.271$ $\mathrm{mmol}, 5 \mathrm{~mL}$ ) and stand at room temperature for 3 days resulting in a clear pink solution. Upon slow evaporation of the solution at room temperature, red block crystals start forming two weeks later. After a month, the crystals were isolated, washed with cold water and then air-dried for overnight (93 mg, 68\%).

\section{Result and Discussion}

\subsection{Synthesis of the complex}

Formation of cobalt(II)-tartrate is based on a simple metathesis reaction between tartaric ions and $\mathrm{Co}(\mathrm{II})$ ions, as follows:

$$
\begin{aligned}
\left(\mathrm{NH}_{4}\right)_{2}\left(\mathrm{C}_{4} \mathrm{H}_{4} \mathrm{O}_{6}\right)_{(\mathrm{aq})}+\mathrm{Co}\left(\mathrm{NO}_{3}\right)_{2(\mathrm{aq})} & \rightarrow 2 \mathrm{NH}_{4} \mathrm{NO}_{3(\mathrm{aq})} \\
& +\mathrm{Co}\left(\mathrm{C}_{4} \mathrm{H}_{4} \mathrm{O}_{6}\right)_{(\mathrm{s})}
\end{aligned}
$$

Diammonium tartrate was used instead of tartaric acid, as frequently used in other works $[11,18,19,21,22]$, since diammonium tartrate gives different level of acidity in an aqueous so- 
lution. The acidity level of reaction condition influences the chemical equilibrium and the chemical species in the solution, thus affecting the crystallization process. Tartaric acid is a weak acid with $p K a_{1}=2.98$ and $p K a_{2}=4.34$ at $25^{\circ} \mathrm{C}$ for $L$-tartaric acid or $p K a_{1}=3.17$ and $p K a_{2}=4.91$ at $25^{\circ} \mathrm{C}$ for meso-tartaric acid [32]. This indicates that the number of tartaric ions $\left(\mathrm{C}_{4} \mathrm{H}_{4} \mathrm{O}_{6}{ }^{2-}\right)$ present in the solution are limited at certain $\mathrm{pH}$ value which eventually affects the stoichiometry and the crystal yield. On the other hand, if we use highly soluble tartaric salt (i.e. $\mathrm{Na}$ or $\mathrm{K}$ salt), the diffusion rate of tartaric ions $\left(\mathrm{C}_{4} \mathrm{H}_{4} \mathrm{O}_{6}{ }^{2-}\right)$ in the solution is very high, therefore tartaric ions react much faster with cobalt(II) ions and amorphous products are likely precipitated.

The cobalt and the diammonium tartrate solutions were prepared in a dilute concentration and they were added slowly, instead of mixed and stirred directly, to avoid direct precipitation. After homogenous clear pink solution was obtained, the solution then slowly evaporated at room temperature by making few holes on the vial lid. Red tiny block crystals start forming after two weeks in which the solution was left for another month to get a bigger crystal and higher yield without leaving the solution to dryness. Hence, in this work, the yield reported here may not be the optimum yield.

In general, crystallization of cobalt(II)tartrate hydrate coordination polymer in aqueous solution remains feasible, affordable because using less chemical and only requires one step reaction. Therefore, investigation on other

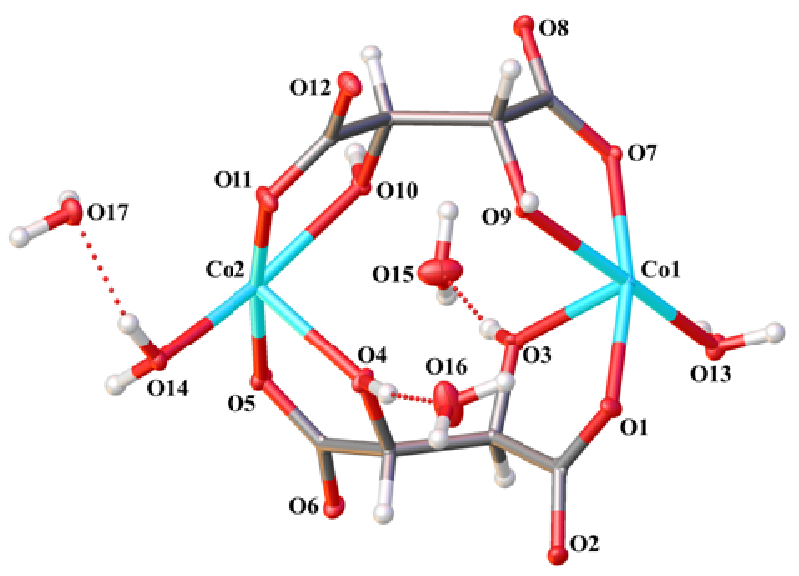

Figure 1. Asymmetric unit of $\left\{\left[\mathrm{Co}_{2}(\mu\right.\right.$ $\left.\left.\mathrm{C}_{4} \mathrm{H}_{4} \mathrm{O}_{6}\right)\left(\mu^{4}-\mathrm{C}_{4} \mathrm{H}_{4} \mathrm{O}_{6}\right)\left(\mathrm{H}_{2} \mathrm{O}\right)_{2}\right] \cdot 3 \mathrm{H}_{2} \mathrm{O}$ ? n shown with thermal ellipsoids at $50 \%$ probability (except hydrogen atoms), hydrogen bonding are shown in red dots (light blue = cobalt, red $=$ oxygen, gray $=$ carbon, white $=$ hydrogen) transition metal tartrate $(\mathrm{M}(\mathrm{II})=\mathrm{Fe}, \mathrm{Mn}, \mathrm{Ni}$, $\mathrm{Cu}, \mathrm{Zn}, \mathrm{Cd}$ ) complexes grown from an aqueous solution using diammonium tartrate is also conducted and their investigation is still ongoing.

\subsection{Crystal structure}

Crystal structure of $\left\{\left[\mathrm{Co}_{2}\left(\mu-\mathrm{C}_{4} \mathrm{H}_{4} \mathrm{O}_{6}\right)(\mu 4\right.\right.$ $\left.\left.\left.\mathrm{C}_{4} \mathrm{H}_{4} \mathrm{O}_{6}\right)\left(\mathrm{H}_{2} \mathrm{O}\right)_{2}\right] \cdot 3 \mathrm{H}_{2} \mathrm{O}\right\}_{\mathrm{n}}$ was solved in orthorhombic space group $P 2{ }_{1}{ }_{2}{ }_{1}{ }_{1}$ with cell parameters: $a=7.8484(2) \AA, b=11.1233(3) \AA, c=$ 18.0812(5) $\AA, a=b=g=90^{\circ}$, and volume $=$ 1578.49(7) A33. These parameters are different to other related paper published previously [11,21,25], but identical to those reported by Ariponnammal and Srinivasan [24]. However, Ariponnammal and Srinivasan's paper only mention a proposed chemical formula of the crystal which was $\left[\mathrm{Co}\left(\mathrm{C}_{4} \mathrm{H}_{4} \mathrm{O}_{6}\right)\right] \cdot 2 \mathrm{H}_{2} \mathrm{O}$, generated from powder XRD analyses, thus the paper was not examining the structure of the complex [24].

The asymmetric unit of the complex consists of two cobalt centres bridged by one tetradentate and one hexadentate dianionic tartaric ion, two water molecules as ligand and three water molecules as lattice solvent (Figure 1). Both octahedral cobalt centre is surrounded by six oxygen atoms, which are from one water oxygen atom, one carboxylate and one hydroxyl oxygen atoms from the tetradentate tartaric ion, one carboxylate and one hydroxyl oxygen atoms from the hexadentate tartaric ion, and one carboxylate oxygen atom from another hexadentate tartaric ion. The chelating carboxylate and hydroxyl groups toward cobalt centre in both tetra- and hexadentate tartaric ions form five-membered chelate ring. Coordination modes of both tetra- and hexa-dentate tartaric ions are presented in Figure 2.

In both cobalt centres, the $\mathrm{Co}-\mathrm{O}$ bond lengths ranges from 2.0348(18) to 2.1427(19) $\AA$,
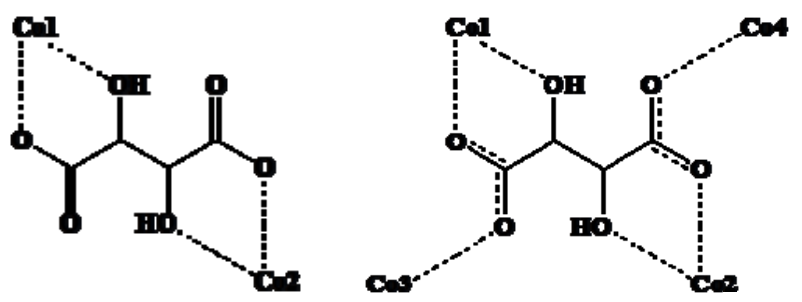

Figure 2. Coordination modes of tetra (left) and hexadentate (right) tartaric ions in the $\left\{\mathrm{Co}_{2}(\mu\right.$ $\left.\left.\left.\mathrm{C}_{4} \mathrm{H}_{4} \mathrm{O}_{6}\right)\left(\mu^{4}-\mathrm{C}_{4} \mathrm{H}_{4} \mathrm{O}_{6}\right)\left(\mathrm{H}_{2} \mathrm{O}\right)_{2}\right] \cdot 3 \mathrm{H}_{2} \mathrm{O}\right\}_{n}\left(\mathrm{Co} 1 \cdots \mathrm{Co}_{2}=\right.$ $5.229 \AA$ A $; \mathrm{Co} 2 \cdots \mathrm{Co} 4=5.447 \AA ; \mathrm{Co} 1 \cdots \mathrm{Co} 3=5.657$ $\AA ; \mathrm{Co} 3 \cdots \mathrm{Co} 4=8.545 \AA$ A) 
whereas the angles ranges from $77.39(8)$ to $173.37(8)^{\circ}$, thus indicating that both cobalt centres have distorted octahedral geometry (Table 1). The $\mathrm{Co} 1 \cdots \mathrm{Co} 2$ distance bridged by both tetra- and hexadentate tartaric ions is $5.229 \AA$ and forming a dinuclear cobalt(II) unit. This hexadentate ligand also bridges two other adjacent cobalt centres and each dinuclear cobalt(II) unit is connected to four neighbouring dinuclear cobalt(II) units, hence the crystal packing displays $2 \mathrm{D}$ polymeric structure (Figure 3). Assuming the tartrate ions as single linker (the chelate ring considered as a single
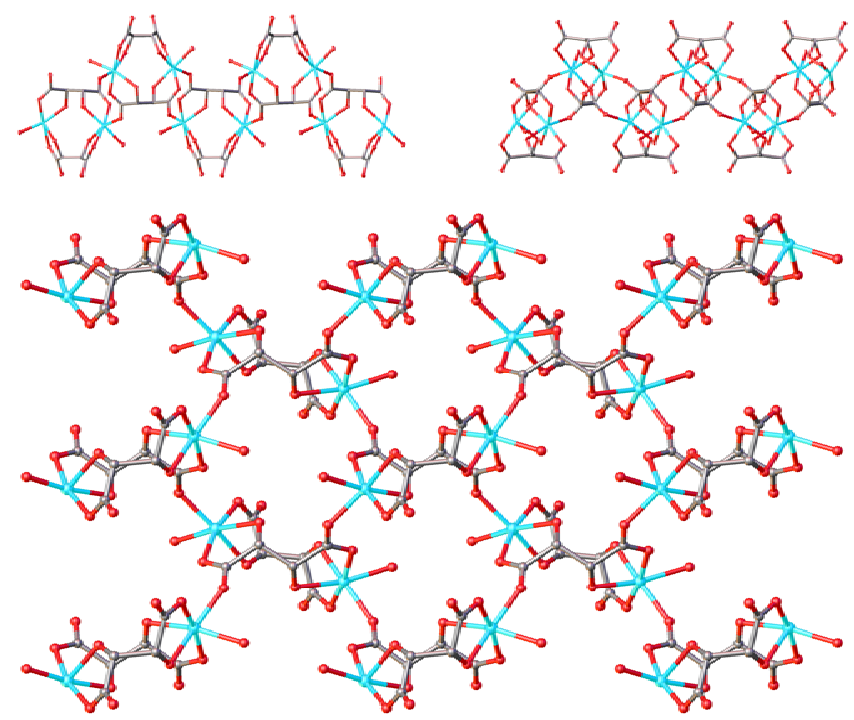

Figure 3. Crystal packing of $\left\{\left[\mathrm{Co}_{2}\left(\mu-\mathrm{C}_{4} \mathrm{H}_{4} \mathrm{O}_{6}\right)\left(\mu^{4}\right.\right.\right.$ $\left.\left.\left.\mathrm{C}_{4} \mathrm{H}_{4} \mathrm{O}_{6}\right)\left(\mathrm{H}_{2} \mathrm{O}\right)_{2}\right] \cdot 3 \mathrm{H}_{2} \mathrm{O}\right\}$ n viewed from $a$ (top left), $b$ (top right), and $c$ axis (bottom), $\mathrm{CH}$ hydrogen atoms and lattice water molecules are omitted for clarity point of connection to metal centre), the cobalt(II) centres exhibits 3-connected nodes, hence the $2 \mathrm{D}$ sheet could be referred to be having a $(6,3)$ topology. Surprisingly, although the asymmetric unit, metal-ligand connectivity and the crystal colour are different, the $(6,3) 2 \mathrm{D}$ coordination polymers resulted in this work has identical topology to coordination polymers reported by Gu and Yang [11].

The $(6,3)$ sheets then grew into 3D hydrogen-bonded networks due to medium to strong hydrogen bonding interaction between the sheets involving lattice water molecules $(\mathrm{O} 15$, 016, 017), hydroxyl groups of the tartrate ligands (O3, O4, O9, O10) and water ligands

Table 2. Hydrogen bond $\mathrm{D} \cdots \mathrm{A}$ distances of the complex

\begin{tabular}{|c|c|c|c|}
\hline D & $\mathbf{H}$ & $\mathbf{A}$ & D $\cdots A(\AA)$ \\
\hline O3 & H3 & $\mathrm{O} 15$ & $2.680(3)$ \\
\hline $\mathrm{O} 4$ & $\mathrm{H} 4$ & O16 & $2.649(3)$ \\
\hline O14 & H14B & O17 & $2.805(3)$ \\
\hline $\mathrm{O} 15$ & $\mathrm{H} 15 \mathrm{~A}$ & O1\#a & $2.825(3)$ \\
\hline O16 & H16B & O5\#b & $2.805(3)$ \\
\hline $\mathrm{O} 17$ & H17A & $\mathrm{O} 7 \# \mathrm{c}$ & $2.743(3)$ \\
\hline O9 & H9 & $\mathrm{O} 17 \# \mathrm{~d}$ & $2.792(3)$ \\
\hline $\mathrm{O} 10$ & $\mathrm{H} 10$ & O17\#e & $2.794(3)$ \\
\hline $\mathrm{O} 13$ & $\mathrm{H} 13 \mathrm{~A}$ & O6\#f & $2.807(3)$ \\
\hline O13 & H13B & $\mathrm{O} 2 \# \mathrm{~g}$ & $2.653(3)$ \\
\hline $\mathrm{O} 14$ & $\mathrm{H} 14 \mathrm{~A}$ & $\mathrm{O} 2 \# \mathrm{~h}$ & $2.686(3)$ \\
\hline \multicolumn{4}{|c|}{ Symmetry: } \\
\hline \multicolumn{4}{|c|}{$\begin{array}{l}\# a=-1+x,+y,+z ; \# b=1+x,+y,+z ; \\
\# c=+x, 1+y,+z ; \# d=1-x,-1 / 2+y, 1 / 2-z ; \\
\# e=-x,-1 / 2+y, 1 / 2-z ; \# f=1 / 2+x, 1 / 2-y, 1+z ; \\
\# g=-1 / 2+x, 1 / 2-y, 1+z ; \# h=-1 / 2+x,{ }^{3} /{ }_{2}-y, 1+z .\end{array}$} \\
\hline
\end{tabular}

Table 1. Selected bond lengths and angles around the cobalt centres

\begin{tabular}{|c|c|c|c|c|c|}
\hline \multicolumn{2}{|c|}{ Bond Lengths $(\AA)$} & \multicolumn{4}{|c|}{ Angles $\left(^{\circ}\right)$} \\
\hline Co1-O7 & $2.0418(19)$ & O7-Co1-O3 & $91.48(8)$ & O4-Co2-O10 & $91.30(8)$ \\
\hline Co1-O3 & $2.117(2)$ & O7-Co1-O13 & $97.86(8)$ & $\mathrm{O} 14-\mathrm{Co} 2-\mathrm{O} 4$ & $89.37(8)$ \\
\hline Co1-O1 & 2.0363(19) & O7-Co1-O9 & $77.96(7)$ & O14-Co2-O8\#2 & $81.11(7)$ \\
\hline Co1-O13 & $2.0577(19)$ & O7-Co1-O12\#1 & $97.10(8)$ & O14-Co2-O1 & $164.08(7)$ \\
\hline Co1-O9 & $2.1427(19)$ & O3-Co1-O9 & $88.21(8)$ & $\mathrm{O} 11-\mathrm{Co} 2-\mathrm{O} 4$ & $94.94(8)$ \\
\hline Co1-O12\#1 & $2.0722(19)$ & O1-Co1-O7 & $167.30(8)$ & $\mathrm{O} 11-\mathrm{Co} 2-\mathrm{O} 14$ & $86.04(8)$ \\
\hline $\mathrm{Co} 2-\mathrm{O} 4$ & $2.1147(19)$ & O1-Co1-O3 & $78.06(7)$ & O11-Co2-O5 & $172.23(8)$ \\
\hline $\mathrm{Co} 2-\mathrm{O} 14$ & $2.0679(19)$ & O1-Co1-O13 & $88.80(8)$ & O11-Co2-O8\#2 & $101.53(8)$ \\
\hline Co2-O11 & 2.0348(19) & O1-Co1-O9 & $94.37(8)$ & $\mathrm{O} 11-\mathrm{Co} 2-\mathrm{O} 10$ & $78.05(7)$ \\
\hline Co2-O5 & $2.0423(18)$ & O1-Co1-O12\#1 & $94.60(8)$ & O5-Co2-O4 & $77.39(8)$ \\
\hline $\mathrm{Co} 2-\mathrm{O} 8 \# 2$ & $2.0756(19)$ & O13-Co1-O3 & $86.76(8)$ & O5-Co2-O14 & $95.02(8)$ \\
\hline $\mathrm{Co} 2-\mathrm{O} 10$ & $2.1328(18)$ & O13-Co1-O9 & $173.37(8)$ & O5-Co2-O8\#2 & $86.24(8)$ \\
\hline \multicolumn{2}{|l|}{ Symmetry: } & O13-Co1-O12\#1 & $81.05(8)$ & $\mathrm{O} 5-\mathrm{Co} 2-\mathrm{O} 10$ & $100.65(8)$ \\
\hline \multicolumn{2}{|c|}{$\# 1=1-x,-1 / 2+y, 1 / 2-z$} & O12\#1-Co1-O3 & $165.93(8)$ & $\mathrm{O} 8 \# 2-\mathrm{Co} 2-\mathrm{O} 4$ & $160.29(7)$ \\
\hline \multicolumn{2}{|c|}{$\# 2=-x, 1 / 2+y, 1 / 2-z$} & O12\#1-Co1-O9 & $104.44(7)$ & $\mathrm{O} 8 \# 2-\mathrm{Co} 2-\mathrm{O} 1$ & $102.58(7)$ \\
\hline
\end{tabular}


(O13, O14). The $\mathrm{D} \cdots \mathrm{A}$ hydrogen bond distancesare varying from 2.649(3) to 2.825(3) $\AA$ (Table 2). Crystallographic data of $\left\{\left[\mathrm{Co}_{2}\left(\mu-\mathrm{C}_{4} \mathrm{H}_{4} \mathrm{O}_{6}\right)\left(\mu^{4}\right.\right.\right.$ $\left.\left.\left.\mathrm{C}_{4} \mathrm{H}_{4} \mathrm{O}_{6}\right)\left(\mathrm{H}_{2} \mathrm{O}\right)_{2}\right] \cdot 3 \mathrm{H}_{2} \mathrm{O}\right\} \mathrm{n}$ is given in Table 3.

\subsection{ATR-IR Analysis}

Table 3. Crystallographic data of $\left\{\left[\mathrm{Co}_{2}(\mu-\right.\right.$ $\left.\left.\left.\mathrm{C}_{4} \mathrm{H}_{4} \mathrm{O}_{6}\right)\left(\mu^{4}-\mathrm{C}_{4} \mathrm{H}_{4} \mathrm{O}_{6}\right)\left(\mathrm{H}_{2} \mathrm{O}\right)_{2}\right] \cdot 3 \mathrm{H}_{2} \mathrm{O}\right\}_{\text {n }}$

\begin{tabular}{|c|c|}
\hline Chemical formula & $\mathrm{C}_{8} \mathrm{H}_{18} \mathrm{Co}_{2} \mathrm{O}_{17}$ \\
\hline Formula Mass & 504.08 \\
\hline Crystal system & Orthorhombic \\
\hline Space group & $P 2{ }_{1} 2_{1} 2_{1}$ \\
\hline$a / \AA$ & $7.8484(2)$ \\
\hline$b / \AA$ & $11.1233(3)$ \\
\hline$c / \AA$ & $18.0812(5)$ \\
\hline$\alpha /{ }^{\circ}$ & 90 \\
\hline$\beta /{ }^{\circ}$ & 90 \\
\hline$\gamma /{ }^{\circ}$ & 90 \\
\hline Unit cell volume $/ \AA^{3}$ & $1578.49(7)$ \\
\hline Temperature/K & $123(2)$ \\
\hline$Z$ & 4 \\
\hline Crystal size (mm) & $0.10 \times 0.15 \times 0.25$ \\
\hline$m\left(\mathrm{~mm}^{-1}\right)$ & 2.198 \\
\hline Completeness & 0.9957 \\
\hline Reflections measured & 15942 \\
\hline Independent reflections & 3955 \\
\hline Observed reflections $(I>2 \sigma(I))$ & 3781 \\
\hline$R_{\text {int }}$ & 0.0273 \\
\hline Final $R_{1}$ values (obs. data) & 0.0222 \\
\hline Final $w R\left(F^{2}\right)$ values (obs. data) & 0.0507 \\
\hline Final $R_{l}$ values (all data) & 0.0240 \\
\hline Final $w R\left(F^{2}\right)$ values (all data) & 0.0517 \\
\hline Goodness of fit on $F^{2}$ & 1.057 \\
\hline
\end{tabular}

In general, the ATR-IR spectrum of $\left\{\left[\mathrm{Co}_{2}(\mu\right.\right.$ $\left.\left.\left.\mathrm{C}_{4} \mathrm{H}_{4} \mathrm{O}_{6}\right)\left(\mu^{4}-\mathrm{C}_{4} \mathrm{H}_{4} \mathrm{O}_{6}\right)\left(\mathrm{H}_{2} \mathrm{O}\right)_{2}\right] \cdot 3 \mathrm{H}_{2} \mathrm{O}\right\}_{\mathrm{n}}$ is also identical to other cobalt(II)-tartrate hydrate reported previously [11,21,24], in which all the characteristic vibrational bands of tartaric ions (namely carboxylate, alkyl, hydroxyl groups) and water hydrate are present (Figure 4). The hydroxyl stretching peaks are observed at 3612 and $3444 \mathrm{~cm}^{-1}$ next to broad peaks around 3300-3100 which indicate the presence of water molecules. These peaks, along with $\mathrm{O}-\mathrm{H}$ inplane bending sharp peak at $1437 \mathrm{~cm}^{-1}$, confirms the hydrous nature of the compound. Several medium peaks are observed around $2900-2700 \mathrm{~cm}^{-1}$ which correspond to the $\mathrm{C}-\mathrm{H}$ alkyl stretch. At 1589 and $1560 \mathrm{~cm}^{-1}$, very sharp peaks of symmetric and asymmetric stretch of the carboxylate groups are noticed. The sharp peaks at $1374,1287,1238,1116$, and $1045 \mathrm{~cm}^{-1}$ were also observed, which is belong to the $\mathrm{C}-\mathrm{O}$ stretch of the tartrate in the compound. In addition, the characteristic $\mathrm{C}-\mathrm{H}$ bending in tartrate are observed at 929 and $712 \mathrm{~cm}^{-1}$.

\section{Conclusions}

Red block coordination polymer of $\left\{\left[\mathrm{Co}_{2}\left(\mu-\mathrm{C}_{4} \mathrm{H}_{4} \mathrm{O}_{6}\right)\left(\mu^{4}-\mathrm{C}_{4} \mathrm{H}_{4} \mathrm{O}_{6}\right)\left(\mathrm{H}_{2} \mathrm{O}\right)_{2}\right] \cdot 3 \mathrm{H}_{2} \mathrm{O}\right\}_{\text {n }}$ crystallizes from aqueous solution at room temperature using diammonium tartrate as the reactant The crystal structure, solved in orthorhombic space group $P 2{ }_{1} 2_{1} 2_{1}$, displays a dinu-

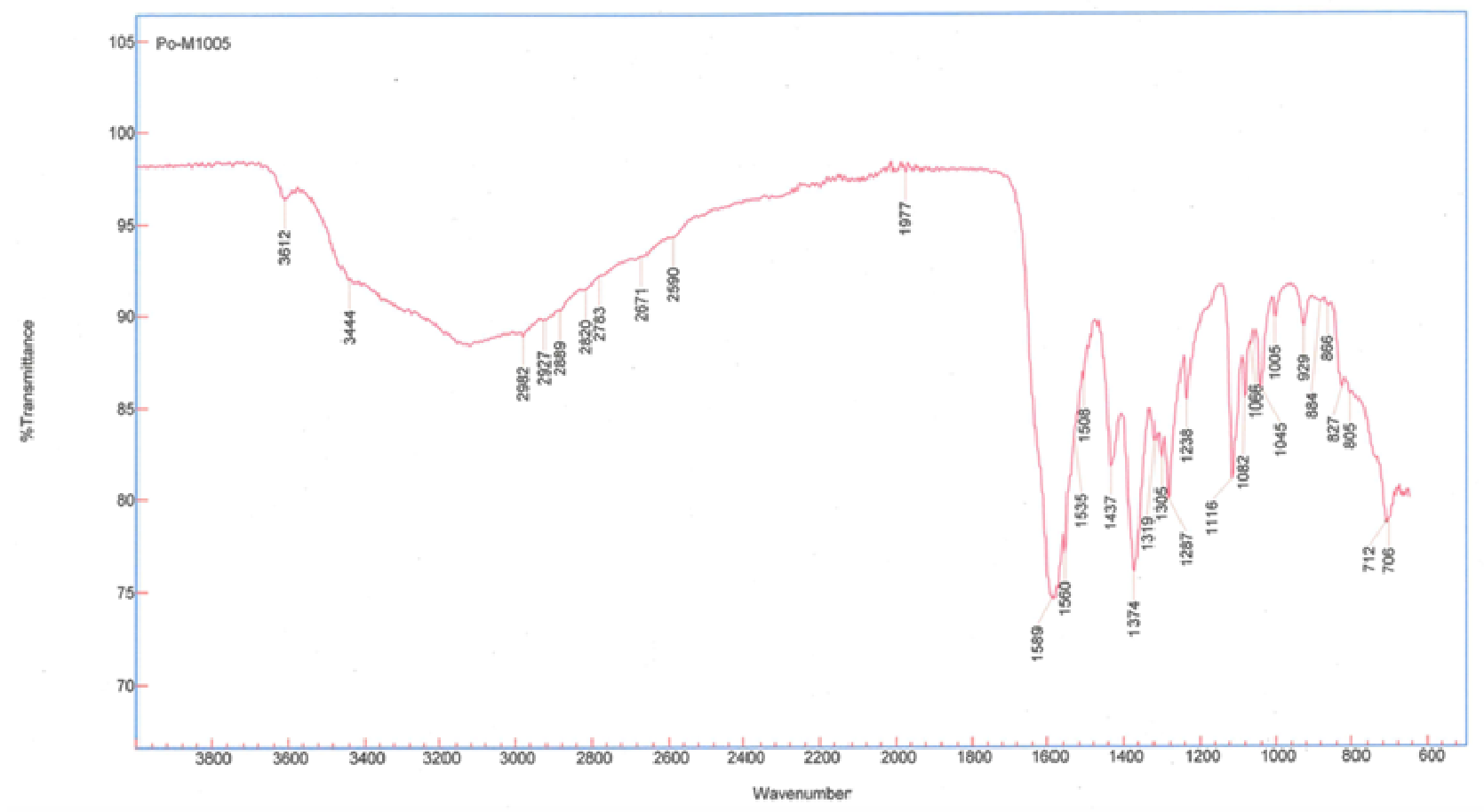

Figure 4. ATR-IR spectrum of the $\left\{\left[\mathrm{Co}_{2}\left(\mu-\mathrm{C}_{4} \mathrm{H}_{4} \mathrm{O}_{6}\right)\left(\mu^{4}-\mathrm{C}_{4} \mathrm{H}_{4} \mathrm{O}_{6}\right)\left(\mathrm{H}_{2} \mathrm{O}\right)_{2}\right] \cdot 3 \mathrm{H}_{2} \mathrm{O}\right\}_{\mathrm{n}}$ 
clear cobalt(II) unit bridged bytetra- and hexadentate dianionic tartaric ions and forms a $(6,3) 2 \mathrm{D}$ sheet which then grew into a $3 \mathrm{D}$ hydrogen-bonded network. Each hexadentate ligand connects four different cobalt centres. This aqueous technique is considered feasible, affordable and simple for the production of functional polymeric cobalt(II)-tartrate hydrate.

\section{Acknowledgment}

Authors thanks the Brawijaya University for the facilities and financial supports. YPP acknowledges the AusAid-DFAT through an Australia Awards Scholarship scheme.

\section{References}

[1] Batten, S.R., Champness, N.R., Chen, X.M., Garcia-Martinez, J., Kitagawa, S., Öhrström, L., O'Keeffe, M., Suh, M.P., Reedijk, J. (2012). Coordination Polymers, Metal-organic Frameworks and the Need for Terminology Guidelines. Crystal Engineering Communication, 14: 3001-3004.

[2] Batten, S.R. (2006). Coordination Polymers, in Encyclopedia of Supramolecular Chemistry, Eds: Atwood J.L. and Steed, J.W. Marcel Dekker, New York, USA. 1-13.

[3] Steed, J.W., Turner, D.R., Wallace, K.J. (2007). Core Concepts in Supramolecular Chemistry and Nanochemistry. John Wiley and Sons, Ltd. Chichester, UK.

[4] Batten, S.R., Neville, S.M., Turner, D.R. (2009). Coordination Polymers: Design, Analysis, and Application, Chapter 1. RSC Publishing. Cambridge, UK.

[5] Prananto, Y.P., Turner, D.R., Lu, J., Batten, S.R. (2009). Solvent-Induced Structural Changes in Complexes of 1,2-Bis(3-(3pyridyl)pyrazolyl)ethane, Australian Journal of Chemistry, 62 (2): 108-114.

[6] Gimeno, N.,Vilar, R. (2006). Anions as Templates in Coordination and Supramolecular Chemistry, Coordination Chemistry Reviews, 250: 3161-3189.

[7] Forster, P.M., Burbank, A.R., Livage, C., Férey, G., Cheetham, A.K. (2004). The Role of Temperature in The Synthesis of Hybrid Inorganic-organic Materials: The Example of Cobalt Succinates, Chemical Communication, 368-369.

[8] Bacsa, J., Eve, D., Dunbar, K.R. (2005). Catena-Poly[[diaquacobalt(II)]- $\mu$-Oxalato]. Acta Crystallographica. C61: m58-m60.

[9] Bouaoud, Y., Setifi, Z., Buvailo, A., Potaskalov, V.A., Merazig, H., Denes, G. (2016). Crys- tal Structure of Poly[diaqua $(\mu-2$ carboxyacetato- $\left.k^{3} \mathrm{O}, \mathrm{O}^{\prime}: \mathrm{O}^{\prime}\right)(2$-carboxyacetatokO)di- $\mu$-chlorido-dicobalt(II)]. Acta Crystallographica. E72: 21-24.

[10] Long, L-S., Chen, X-M., Tong, M-L., Sun, ZG., Ren, Y-P., Huang, R-B., Zheng, L-S. (2001). A Unique Open Inorganic-Organic Framework with Alternate Hexa- and PentaCoordinate Cobalt(II) Sites. Synthesis, Crystal Structure,and Magnetic Properties of $\left[\mathrm{Co}_{3}\left(\mathrm{C}_{4} \mathrm{H}_{4} \mathrm{O}_{4}\right)_{2.5}(\mathrm{OH})\right]_{\mathrm{n}} \cdot 0.5_{\mathrm{n}} \mathrm{H}_{2} \mathrm{O}$. Journal of Chemical Society, Dalton Transaction. 28882890.

[11] Gu, Y., Yang, M. (2008). Synthesis, Characterization of An Unusual Crystalline Material with Tartrate. Crystal Research and Technology. 43 (12): 1331-1334.

[12] Croitor, L., Chisca, D., Coropceanu, E.B., Volodina, G.F., Petuhov, O., Fonari, M.S. (2017). Solvent-rich Layered Cobalt(II) 1,4benzenedicarboxylate Based on Binuclear $\left\{\mathrm{Co}_{2}\left(\mu-\mathrm{OH}_{2}\right)(\mathrm{RCOO})_{2}\right\} \quad$ Secondary Building Unit. Journal of Molecular Structure, 1137: 136-141.

[13] Ramajothi, J., Danuskodi, S. (2003). Optical and Microhardness Studies of Semiorganic Nonlinear Optical Material: L-histidine Tetrafluoroborate. Crystal Research and Technology, 38 (11): 986-991.

[14] Cantrell, J.H. (2010). Handbook of Metrology, Chapter 7. Ultrasonics, Eds. Glaser, M., Kochsiek, M., Wiley-VCH Verlag GmbH \& Co. KGaA, Weinheim, Germany.

[15] Gon, H.B. (1990). Ferroelectricity in Calcium Tartrate Single Crystals Grown by Gel Technique. Journal of Crystal Growth, 102: 501504.

[16] Desai, C.C., Patel, A.H. (1987). Some Aspects of Electrical Conductivity of Ferroelectric Rubidium Tartrate Single Crystals. Journal ofMaterial Science Letter, 6: 1066-1068.

[17] Abdel-Kader, M.M., El-Kabbany, F., Taha, S., Abosehly, M., Tahoon, K.K., El-Sharkawy, A.A. (1991). Thermal and Electrical Properties of Ammonium Tartrate. Journal of Physics and Chemistry of Solids, 52 (5): 655-658.

[18] Yadava, V.S., Padmanabhan, V.M. (1973). The Crystal Structure of Ammonium Tartrate. Acta Crystallographica. B29: 493-498.

[19] Shajan, X.S., Mahadevan, C. (2005). FT-IR Spectroscopic and Thermal Studies on Pure and Impurity added Calcium Tartrate Tetrahydrate Crystals. Crystal Research and Technology, 40 (6): 598-602.

[20] Prananto, Y.P., Khunur, M.M., Wahyuni, D.T., Shobirin, R.A., Nata, Y.R., Riskah, E. 
(2013). Study of Gel Growth Cobalt (II) Oxalate Crystals as Precursor of $\mathrm{Co}_{3} \mathrm{O}_{4}$ Nano Particles. Bulletin of Chemical Reaction Engineering \& Catalysis, 7 (3): 198-204.

[21] Mathivanan, V., Haris, M., Prasanya, T., Amgalan, M. (2014). Synthesis and Characterization of Gel-grown Cobalt Tartrate Crystals, Pramana - Journal of Physics, 82 (3): 537-548.

[22] Nandre, S.J., Shitole, S.J., Ahire, R.R. (2013). FT-IR, Thermal and Optical Studies of Gel Grown Cobalt Tartrate Crystals, Journal of Nano and Electronic Physics, 5 (4): 04050-104050-5.

[23] Desai, C.C., Patel, A.H. (1988). Crystal Data for Ferroelectric $\mathrm{RbHC}_{4} \mathrm{H}_{4} \mathrm{O}_{6}$ and $\mathrm{NH}_{4} \mathrm{HC}_{4} \mathrm{H}_{4} \mathrm{O}_{6}$ Crystals, Journal of Materials Science Letter, 7: 371-373.

[24] Ariponnammal, S., Srinivasan, T. (2014). Growth and Spectroscopic Characterization of Cobalt Tartrate Crystals. Research Journal of Recent Sciences, 3: 63-66.

[25] Du, C-J., Zhang, Q-A., Wang, L-S., Du, C-L. (2012). Diaquabis(hydrogentartrato)cobalt(II) dihydrate, Acta Crystallographica. E68: m99m100.

[26] Bruker AXS Ltd. (2005). APEX2. Madison. Wisconsin, USA.

[27] Sheldrick, G.M. (1996). SADABS. University of Göettingen, Germany.

[28] Sheldrick, G.M. (2008). A Short History of SHELX. Acta Crystallographica. A64: 112122.

[29] Sheldrick, G.M. (1997). SHELXS97, Program for the Solution of Crystal Structures. University of Göttingen, Germany.

[30] Sheldrick, G.M. (1997). SHELXL97, Program for the Refinement of Crystal Structures. University of Göttingen, Germany.

[31] Dolomanov, O.V., Bourhis, L.J., Gildea, R.J., Howard, J.A.K., Puschmann, H. (2009). OLEX2: A Complete Structure Solution, Refinement, and Analysis Program. Journal of Applied Crystallography, 42: 339-341.

[32] Lide, D.R. (2010). Dissociation Constants of Organic Acids and Bases, in CRC Handbook of Chemistry and Physics, 90 ${ }^{\text {th }}$ ed. (CD-ROM Version). CRC Press/Taylor and Francis, Boca Raton, Florida, USA. 